\title{
TAMAN HEWAN PELIHARAAN DAN TEATER KEBON JERUK
}

\author{
Judy Christiana1), Petrus Rudi Kasimun²) \\ 1) Program Studi S1 Arsitektur, Fakultas Teknik, Universitas Tarumanagara, chris-yeo@live.com \\ 2) Program Studi S1 Arsitektur, Fakultas Teknik, Universitas Tarumanagara, rudi.kasimun@gmail.com
}

\begin{abstract}
Abstrak
Manusia selalu mencari sesuatu di luar apa yang mereka temukan di rumah atau di tempat kerja. Dengan pesatnya pertumbuhan kependudukan dan ekonomi di Indonesia, Jakarta menjadi salah satu kota dengan pembangunan First Place dan Second Place yang tinggi. Kebutuhan akan Third place meningkat sebagai wadah alternatif dan penyeimbang pertumbuhan kota. Hewan pendamping dapat menjadi katalisator untuk beberapa dimensi hubungan dan interaksi personal dan sosial, hingga pembentukan persahabatan/komunitas baru. Mengingatnya semakin banyak bukti isolasi sosial sebagai faktor resiko kesehatan, hewan pendamping menjadi faktor penting dalam mengembangkan lingkungan yang sehat. Kebon Jeruk, Jakarta Barat sangat mendominasi dalam pembangunan First dan Second Place. Sebagai wilayah pemilikan hewan yang cukup tinggi, dari hasil survey dan analisis, hal ini menghambat para pecinta hewan karena peraturan setempat yang cenderung mengakibatkan para pemilik hewan untuk tidak dapat membawa hewan peliharaannya ke tempat umum secara aman dan leluasa. Taman Hewan Peliharaan dan Teater Kebon Jeruk ditujukan sebagai sebuah wadah untuk warga penduduk baik pecinta hewan maupun bukan di sekitarnya yang dapat menggabungkan teori dasar Third place dengan program yang sesuai untuk kebutuhan para penduduk perumahan, pekerja, mahasiswa/murid, dan pengguna fasilitas kesehatan sekitar yang berfokus pada hubungan antara manusia dengan hewan peliharaannya guna meningkatkan kualitas hidup dalam bentuk fisik maupun mental dan meningkatkan toleransi dan pengetahuan masyarakat akan manfaat hewan peliharaan terhadap kehidupan sehari-hari.
\end{abstract}

Kata Kunci: hewan peliharaan; komunitas; mediator; sosialisasi

\begin{abstract}
People are always looking for something outside of what they find at home or at work. With the rapid population and economic growth in Indonesia, Jakarta has become one of the cities with the highest First and Second Place developments. The need for Third places is increasing to balance city growth as an alternative space. Companion animals can be a catalyst for several dimensions of personal and social relationships and interactions, to the formation of new friendships / communities. Given the increasing evidence of social isolation as a health risk factor, companion animals are an important factor in developing a healthy environment. Kebon Jeruk, West Jakarta has one of the most dominant First and Second Place developments. Based on survey results and analysis, as an area with one of the highest animal owners, this has hindered animal lovers from bringing their pets to public spaces safely and freely because of local regulations. Kebon Jeruk Pet Park and Theater is intended as a forum for residents of the surrounding population, for both animal lovers and other users that can intergrate basic Third place theories with programs suitable for the needs of housing residents, workers, students, and users of nearby health facilities that focuses on the relationship between humans and their pets to improve the quality of life both physically and mentally as well as increase public tolerance and knowledge of the benefits of pets on daily life.
\end{abstract}

Keywords: Pets; community; mediator; socialization 


\section{PENDAHULUAN}

Manusia selalu mencari sesuatu di luar apa yang mereka temukan di rumah atau di tempat kerja. Sebagai spesies, manusia selalu membutuhkan tempat-tempat di mana mereka merasa aman, rasa kebersamaan dengan suasana yang hanya dapat diciptakan dalam sebuah ruangan melalui komunitas. Dalam masyarakat modern, kebutuhan ini tidak tercakup secara eksklusif di rumah atau di tempat kerja. Melalui sosialisasi, orang belajar mengidentifikasi apa yang penting dan dihargai dalam budaya tertentu.

Dengan pesatnya pertumbuhan kependudukan dan ekonomi di Indonesia, terutamanya di kota-kota besarnya, Jakarta telah menjadi salah satu kota yang terdampak era fenomena global dimana sifat individualisme semakin meningkat dan sebaliknya hubungan dan relasi sosial menurun akibat peningkatan pembangunan sosial-ekonomi, Kota Jakarta menjadi salah satu kota dengan perkembangan pembangunan First Place dan Second Place yang tinggi. Tetapi manusia selalu mencari sesuatu di luar apa yang mereka temukan di rumah atau di tempat kerja, dalam masyarakat modern, kebutuhan ini tidak tercakup secara eksklusif di tempat-tempat tersebut saja. Fungsi Third place bukanlah hal baru dan telah lama menjadi sesuatu yang penting.

Kebon Jeruk, Jakarta Barat merupakan salah satu tempat yang mempunyai pembangunan First dan Second Place yang mendominasi. Sebagai kota administrasi dengan pemilik hewan tertinggi, hal ini menghambat para pecinta hewan karena peraturan setempat yang cenderung mengakibatkan para pemilik hewan untuk tidak dapat membawa hewan peliharaannya ke tempat umum dengan aman dan leluasa.

Penelitian menunjukkan bahwa hewan pendamping dapat menjadi katalisator untuk beberapa dimensi hubungan sosial manusia di lingkungan sekitar, mulai dari interaksi sosial insidental dan mengenal orang, hingga pembentukan persahabatan baru. Bagi banyak pemilik hewan peliharaan, hewan peliharaan mereka juga memfasilitasi hubungan dimana mereka memperoleh bentuk dukungan sosial yang nyata, baik yang bersifat praktis maupun yang mendukung secara emosional. Mengingatnya semakin banyak bukti untuk isolasi sosial sebagai faktor risiko kesehatan mental dan sebaliknya, persahabatan dan dukungan sosial sebagai faktor perlindungan bagi kesejahteraan individu dan masyarakat, hewan peliharaan mungkin menjadi faktor penting dalam mengembangkan lingkungan yang sehat ${ }^{1}$.

Potensi proyek juga ditunjang dengan sebuah riset bahwa sejak dari tahun 2018, Indonesia merupakan negara ketiga dengan tingkat kepemilikan binatang peliharaan tertinggi di Asia Tenggara. Perubahan gaya hidup konsumen dan peningkatan pendapatan pemakaian di negaranegara Asia Tenggara mendorong peningkatan penerimaan untuk hewan peliharaan, tidak hanya di antara kelompok berpenghasilan tinggi, tetapi juga kelompok berpenghasilan menengah, kepemilikan hewan peliharaan di Indonesia menjadi tren dengan meningkatnya urbanisasi negara².

Kebon Jeruk, Jakarta Barat, khususnya di area sekitar Jl. Arjuna Selatan mempunyai tingkat fungsi bangunan seperti perumahan, kantor, universitas, sekolah, dan fasilitas kesehatan yang tinggi. Taman Hewan Peliharaan dan Teater Kebon Jeruk ditujukan sebagai wadah untuk kebutuhan pengguna sekitarnya dengan program-program yang disesuaikan untuk meningkatkan kualitas hidup para penggunanya secara fisik, mental maupun dalam pembentukan kehidupan komunitasnya.

Perancangan proyek ini mempunyai beberapa masalah yang harus dijawab seperti program seperti apakah yang dapat membantu perkembangan sosial pengguna sekitar melalui hewan peliharaan sebagai mediator, Third place seperti apakah yang dapat menfasilitasi pecinta hewan dalam kehidupan sehari-hari dalam pembentukan komunitas yang mengutamakan kebutuhan

\footnotetext{
${ }^{1}$ Wood L, Martin K, Christian H, Nathan A, Lauritsen C, Houghton S, et al. (2015) The Pet Factor - Companion Animals as a Conduit for Getting to Know People, Friendship Formation and Social Support. PLoS ONE 10(4): e0122085.

${ }^{2}$ https://www.petfairasia.com/en/asia-markets/southeast-asia-pet-market/. (1/24/2020)
} 
sosial pengguna-penggunanya dan dapat meningkatkan kesehatan fisik dan mental melalui hewan peliharaan, juga dapat meningkatkan koneksi emosional dan toleransi masyarakat umum terhadap hewan peliharaan.

Batasan penelitian untuk perancangan proyek meliputi keperluan penduduk dan pengunjung sekitar Kebon Jeruk, tepatnya di pembangunan sekitar Jl. Arjuna Selatan, hubungan antara manusia dengan hewan, hubungan antara manusia dengan manusia lainnya dengan memanfaatkan hewan sebagai mediator, dan pembentukan Third place yang dapat mewadahi pembentukan komunitas dan meningkatkan hubungan sosial antar penggunanya.

Tujuan penulisan ini adalah sebagai bagian dari proses perancangan proyek yang dapat memenuhi kebutuhan pengguna sekitar Kebon Jeruk dengan menciptakan sebuah wadah yang dapat digunakan untuk membangun kembali hubungan sosial, pembentukan komunitas dan peningkatan kualitas hidup dalam bentuk fisik maupun mental penggunanya dengan memanfaatkan hewan peliharaan sebagai mediator dan katalis pembentukan hubungan baru antar individual. Proyek ini juga bertujuan untuk memberikan pandangan moral dan meningkatkan kesadaran manusia terhadap kehidupan hewan sebagai sebuah species.

\section{KAJIAN LITERATUR}

Ray Oldenburg menyebut "First Place" seseorang sebagai rumah dan tempat tinggal seseorang. "Second Place" adalah tempat kerja - di mana orang mungkin menghabiskan sebagian besar waktu mereka. Maka, Third place adalah "jangkar" kehidupan komunitas dan memfasilitasi dan mendorong interaksi yang lebih luas dan lebih kreatif ${ }^{3}$. Dengan kata lain, "Third place Anda adalah di mana Anda bersantai di depan umum, di mana anda berjumpa dengan wajah-wajah yang akrab dan berkenalan baru."

Menurut Oldernburg, Third place adalah tempat-tempat umum di tanah netral di mana orang dapat berkumpul dan berinteraksi. Berbeda dengan First Place (rumah) dan Second Place (bekerja), Third place memungkinkan orang untuk mengesampingkan kekhawatiran mereka dan hanya menikmati kehadiran dan percakapan di sekitar mereka. Third place "menyelenggarakan pertemuan individu, reguler, sukarela, informal, dan yang dengan gembira diantisipasi di luar rumah dan pekerjaan. ${ }^{5}$

Edward Soja mengangkat teori Thirdspace dari Trialectics of Spatiality oleh Henri Lefebvre dan Michael Foucault dalam bukunya "The Production of Space" yang mendefinisikan menjadi tiga yaitu Firstspace, Secondspace, dan Thirdspace. ${ }^{6}$ Dalam teori Trialectics of Spatiality, Thirdspace adalah di mana "Semuanya menjadi satu, subjektivitas dan obyektivitas, yang abstrak dan yang konkret, yang nyata dan yang dibayangkan, yang dapat diketahui dan yang tak terbayangkan, yang berulang dan diferensial, struktur dan agensi, pikiran dan tubuh, kesadaran dan alam bawah sadar, disiplin dan transdisipliner, kehidupan sehari-hari dan sejarah tanpa akhir." ${ }^{17}$

Dalam peran hewan peliharaan terhadap kehidupan sosial dan keseharian, menurut riset dari "The Pet Factor - Companion Animals as a Conduit for Getting to Know People, Friendship Formation and Social Support" yang dipublikasikan pada tahun 2015, hewan peliharaan dapat memberi pemiliknya lebih dari sekadar persahabatan, mereka juga dapat membantu menciptakan persahabatan antar manusia dan dukungan sosial, yang keduanya baik untuk kesehatan jangka panjang. Untuk mengeksplorasi bagaimana hewan peliharaan membantu orang membentuk koneksi sosial, peneliti dari University of Western Australia, Harvard T.H. Sekolah Kesehatan Masyarakat Chan, dan Pusat Nutrisi Pet WALTHAM mensurvey hampir 2.700 pria dan wanita, menjadi pemilik hewan peliharaan adalah cara ketiga yang paling umum yang

\footnotetext{
3 Pete, M. (2012). Going Home: Essays, Articles, and Stories in Honour of the Andersons. Lulu.com. p. 37. ISBN 9781-291-12167-4.

${ }^{4}$ White, Rebekah (July-August 2018). "A third place". New Zealand Geographic (152): 6

5 Oldenburg, R. (1999). Great Good Place. New York: Marlow. p.16

${ }^{6}$ Lefebvre H. (1974). The Production Of Space . Blackwell.

${ }^{7}$ Soja, Edward W. (1996). Thirdspace. Malden (Mass.): Blackwell.
} 
dikatakan oleh responden survei yang membantu mereka bertemu orang-orang di lingkungan mereka. (No. 1 adalah dengan menjadi tetangga; no. 2 adalah dengan menggunakan jalan dan taman setempat.) Pemilik hewan peliharaan $60 \%$ lebih mungkin dibandingkan dengan yang tidak memiliki hewan peliharaan untuk dapat mengenal orang-orang di lingkungan mereka yang belum mereka kenal sebelumnya. Penelitian mereka juga menunjukkan bahwa hewan pendamping dapat menjadi katalisator untuk beberapa dimensi hubungan sosial manusia di lingkungan sekitar, mulai dari interaksi sosial insidental dan mengenal orang, hingga pembentukan persahabatan baru. Bagi banyak pemilik hewan peliharaan, hewan peliharaan mereka juga memfasilitasi hubungan dimana mereka memperoleh bentuk dukungan sosial yang nyata, baik yang bersifat praktis maupun yang mendukung secara emosional. ${ }^{8}$ Mengingatnya semakin banyak bukti untuk isolasi sosial sebagai faktor risiko kesehatan mental, dan, sebaliknya, persahabatan dan dukungan sosial sebagai faktor perlindungan bagi kesejahteraan individu dan masyarakat, hewan peliharaan mungkin menjadi faktor penting dalam mengembangkan lingkungan yang sehat.

Hewan pendamping dapat meningkatkan kesehatan jantung dengan menurunkan tekanan darah dan mengatur detak jantung dalam situasi stres. Dalam sebuah studi tahun 2002, para peneliti mengukur perubahan dalam detak jantung dan tekanan darah di antara orang-orang yang memiliki anjing atau kucing, dibandingkan dengan mereka yang tidak, ketika peserta berada di bawah tekanan (melakukan tugas matematika dengan waktu terhitung). ${ }^{9}$

Penelitian menunjukkan bahwa dukungan sosial yang diberikan hewan peliharaan dapat membuat seseorang merasa lebih rileks dan mengurangi stres. Dukungan sosial dari teman dan keluarga dapat memiliki manfaat yang serupa, tetapi hubungan interpersonal sering menyebabkan stres juga, sedangkan hewan peliharaan lebih cenderung tidak menyebabkan stres. Dukungan sosial yang diberikan oleh hewan peliharaan juga dapat mendorong lebih banyak interaksi sosial dengan orang-orang, mengurangi perasaan terisolasi atau kesepian. ${ }^{10}$

Para peneliti juga menggunakan hewan dalam waktu sementara untuk memberikan persahabatan dengan anak-anak dengan masalah kesehatan atau kesehatan mental, atau orang tua yang mungkin tidak memiliki energi atau sumber daya untuk hewan peliharaan yang tinggal bersama. Beberapa temuan positif dari interaksi dengan anjing terapi termasuk penurunan tingkat rasa sakit dan kecemasan di antara anak-anak dan orang dewasa yang dirawat di rumah sakit, serta peningkatan fokus dan interaksi antara anak-anak dengan autisme dan gangguan perkembangan lainnya. ${ }^{11}$

Diantara orang tua, kepemilikan hewan peliharaan mungkin juga menjadi sumber penting dukungan sosial yang meningkatkan kesejahteraan. Dalam sebuah penelitian, individu lanjut usia yang memiliki anjing atau kucing lebih mampu melakukan aktivitas fisik tertentu yang dianggap sebagai "aktivitas hidup sehari-hari," seperti kemampuan untuk menaiki tangga; membungkuk, berlutut, atau membungkuk; minum obat; menyiapkan makanan; dan mandi dan berpakaian sendiri. Tidak ada perbedaan signifikan antara pemilik anjing dan kucing dalam kemampuan mereka untuk melakukan kegiatan ini. Baik lamanya waktu memiliki anjing atau kucing maupun tingkat keterikatan pada hewan tidak memengaruhi kemampuan kinerja. Dalam pengaturan panti jompo, interaksi dengan anjing mengunjungi telah menyebabkan lebih banyak

\footnotetext{
${ }^{8}$ Wood L, Martin K, Christian H, Nathan A, Lauritsen C, Houghton S, et al. (2015) The Pet Factor - Companion Animals as a Conduit for Getting to Know People, Friendship Formation and Social Support. PLoS ONE 10(4): e0122085

${ }^{9}$ Allen K, Blascovich J, Mendes WB (2002). Cardiovascular reactivity and the presence of pets, friends, and spouses: the truth about cats and dogs. Psychosom Med. Sep-Oct;64(5):727-39.

10 McNicholas J, Collis GM (2000). Dogs as catalysts for social interactions: robustness of the effect. Br J

Psychol;91:61-70.

11 Johnson RA (2011). Animal-assisted interventions in health care contexts. In McCardle P, McCune S, Griffin JA \& Maholmes V (Eds.), How animals affect us (pp. 183-192). Washington D.C.: American Psychological Association.
} 
perilaku sosial, lebih banyak interaksi di antara penghuni, dan lebih sedikit kesepian. ${ }^{12}$

Studi retrospektif dari orang-orang di kursi roda yang memiliki hewan peliharaan melaporkan pengalaman mereka dengan orang asing di tempat umum sebelum dan setelah mendapatkan hewan peliharaan mereka. Hipotesis spesifik yang diuji adalah bahwa perolehan anjing layanan akan meningkatkan jumlah pendekatan ramah oleh orang asing. Subjek dengan anjing layanan melaporkan lebih banyak mendapatkan pendekatan-pendekatan daripada kelompok tanpa anjing.

Kelebihan anjing peliharaan pada orang lumpuh di kursi roda sudah dikenal luas. Anjinganjing semacam itu dapat mengambil benda-benda dan menarik kursi rodanya, misalnya. Namun, kelebihan utama anjing peliharaan pada kenyataannya adalah pengaruh yang kurang dihargai yang mereka miliki dalam memfasilitasi interaksi dan penerimaan sosial.

Beberapa tokoh terkemuka juga mempunyai gagasan mengenai pandangan moral terhadap hewan. Misalnya, Peter Albert David Singer, seorang filsuf moral asal Australia. la adalah Profesor Bioetika Ira W. DeCamp di Princeton University, dan Profesor Laureate di Centre for Applied Philosophy and Public Ethics di University of Melbourne. Singer berpendapat bahwa manusia dan hewan memiliki kesetaraan yang sama, dalam kapasitas untuk menderita atau menikmati hidup mereka. Dan dalam hal ini kita berbagi kesetaraan moral dengan hewan. Dia berkata, "Saya berpikir dalam hal kesetaraan antara manusia dan hewan, dalam arti yang sangat spesifik, dimana mereka berbagi kesetaraan yang penting, adalah kapasitas untuk menderita atau menikmati kehidupan mereka. Ini menjadi moral kesetaraan, di mana rasa sakit mereka seharusnya sepenting rasa sakit manusia, sama halnya, kesenangan mereka sama berharganya dengan kesenangan manusia. Hal yang saya tentang adalah mensepelekan atau mengabaikan rasa sakit makhluk-makhluk hewan hanya karena mereka bukan anggota dari spesies kita, saya ingin memperluas kesetaraan di luar batas spesies. Kita harus memberikan pertimbangan yang sama untuk kepentingan semua makhluk, semua makhluk memiliki kepentingan, semua dapat merasakan sakit, terlepas dari spesies mereka, sama seperti manusia tidak berbeda terlepas dari jenis kelamin, ras, atau warna kulit mereka. Kesetaraan seperti itulah yang ingin saya perdebatkan."13

Lalu Tom Regan, seorang filsuf asal Amerika Serikat yang berspesialisasi di teori hak akan hewan. Dia berpendapat bahwa hewan yang bukanlah manusia adalah "subyek kehidupan", seperti halnya manusia, dan bahwa, jika kita ingin menganggap nilai semua manusia terlepas dari kemampuan mereka untuk menjadi agen yang rasional, maka agar konsisten, kita juga harus mengaplikasikannya ke hewan yang bukan manusia. ${ }^{14}$

Wohlleben, seorang rimbawan dan penulis Jerman menulis tentang tema ekologis di dalam bukunya (The Inner Life of Animals: Love, Grief, and Compassion) bergagasan bahwa walaupun kita benar-benar berbeda dari hewan lain, kesamaan dalam kehidupan kognitif, emosi, dan moral kita tidak hanya mengejutkan dan menakutkan, tetapi juga sangat nyata. Dan, kita harus menggunakan informasi ini atas nama mereka di dunia yang semakin didominasi manusia. la mengatakan bahwa meski manusia dan hewan memiliki tingkat intelijensi yang berbeda, tetapi masing-masing mempunyai cara berkomunikasi, beradapatasi, bersosialitas, dan pertahanan hidup yang tinggi, meski tidak selalu melalui cara yang manusia sudah biasa menggangap hebat dengan kecerdasan-kecerdasan emosional dan kognitif yang unik. Wohlleben mempertanyakan ulang cara manusia mengintepretasikan kasih sayang, keberanian dan sebagainya agar manusia dapan lebih memahami hewan dalam kehidupan sehari-harinya dan berargumen bahwa hanya karena mereka melalukan hal-hal dengan cara berbeda dari manusia akan tetapi hal itu tidak menjadi pengertian bahwa mereka adalah sebuah specias yang inferior.

\footnotetext{
${ }^{12}$ Raina P, Waltner-Toews D, Bonnett B, Woodward C, Abernathy T (1999). Influence of companion animals on the physical and psychological health of older people: an analysis of a one-year longitudinal study. J Am Geriatr Soc. Mar;47(3):323-9.

${ }^{13}$ Singer P. (1975). Animal liberation: A New Ethics for our Treatment of Animals. New York

${ }^{14}$ Regan, T. (1983). The Case for Animal Rights. University of California Press.
} 


\section{METODE PENELITIAN}

1. Subjek Penelitian : Penduduk warga Pemukiman Kebon Jeruk Baru, Pekerja.

2. Objek Penelitian : Jl. Kebon Jeruk, Jeruk Baru, Kebon Jeruk, RT. 8/RW. 8, Kebon Jeruk, Kec. Kebon Jeruk, Kota Jakarta Barat. Daerah Khusus Ibukota Jakarta, 11530.

3. Unsur yang diteliti: Kebiasaan penduduk sekitar, kebutuhan yang tidak terdapatkan pada area tapak, interaksi antara hewan dan pemiliknya.

4. Pengumpulan data: Observasi, studi kasus, studi pustaka, interview.

5. Sumber data : Primer (observasi tapak), sekunder (literatur, peraturan pemerintah).

Metode penelitian yang digunakan adalah penelitian deskriptif. Penelitian deskriptif, menurut Suryana (2010), adalah metode yang digunakan untuk mencari unsur-unsur, ciri-ciri, sifat-sifat suatu fenomena. Dimulai dengan mengumpulkan data, menganalisis data, lalu diinterpretasikan.

Tabel 1. Data Peraturan Pembangunan

\begin{tabular}{ccccc}
\hline KDB & KLB & KB & KDH & KTB \\
\hline $30 \%$ & 1.6 & 8 & $45 \%$ & $40 \%$ \\
\hline
\end{tabular}

Sumber: www.jakarta.go.id, 2020

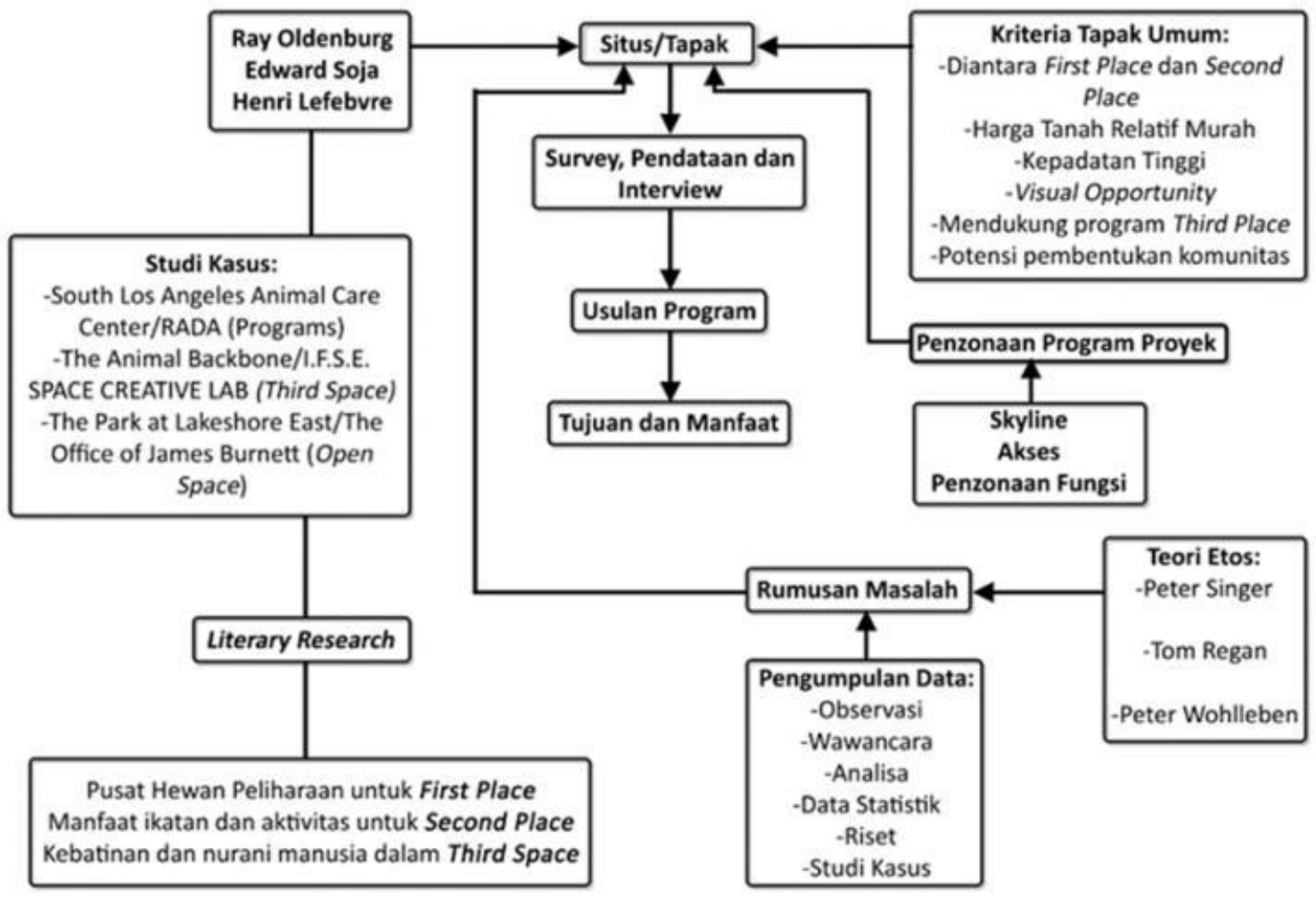

Gambar 1. Bagan Kerangka Berpikir

Sumber: Penulis, 2020

Melalui observasi dan wawancara dengan warga dan pekerja setempat dapat terdata jumlah kediaman yang memiliki hewan peliharaan di kawasan pemukiman Perumahan Kebon Jeruk Baru, didalam komplek yang berjumlah 20-30 rumah per blok, diperkirakan perumahan yang memiliki hewan peliharaan adalah sebanyak $10-50 \%$. Akan tetapi di area perumahan dan RPTRA Jeruk Manis tidak diperbolehkannya membawa jalan-jalan hewan peliharaan dengan alasan kebersihan lingkungan dan keselamatan. Akan tetapi dapat dilihat bahwa tetap cukup banyak warga yang membawa keluar peliharaannya untuk mengelilingi komplek akibat tidak terdapatnya tempat/ruang lainnya yang dapat diutilitaskan. 


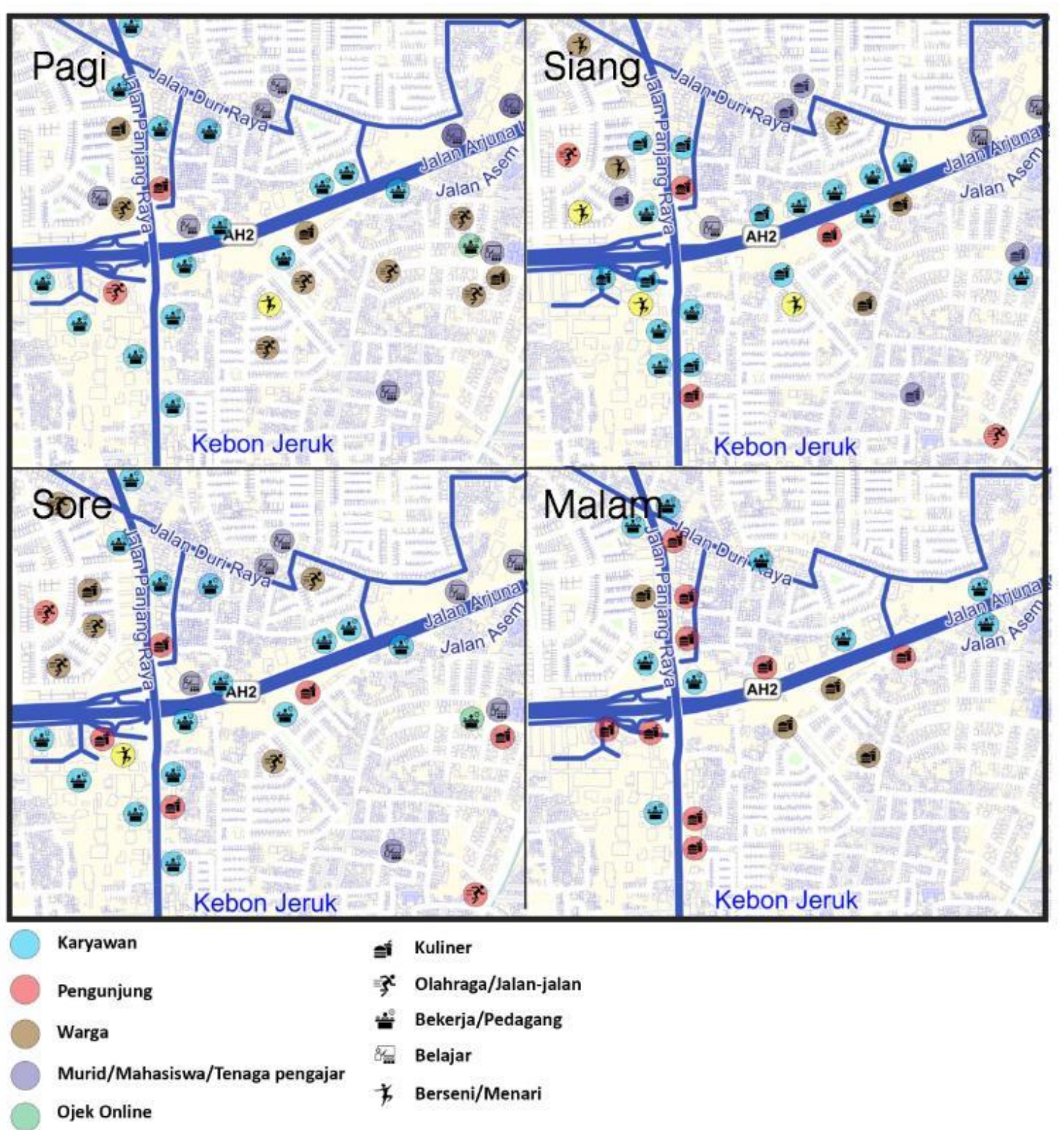

Gambar 2. Aktivitas Pengguna Sekitar Sumber: Penulis, 2020

Dari hasil mapping aktifitas diatas dapat dikonklusikan bahwa area sekitar Jl. Arjuna Selatan didominasi oleh pekerja kantoran dan mahasiswa/murid. Kegiatan berseni/menari dan olahraga berlangsung di RPTRA Kebon Jeruk Manis sedangkan kegiatan lainnya tersebar di seluruh kawasan sekitar. Pada malam hari cenderung tidak ada aktifitas informal yang menggunakan fasilitas di sekitar area. Dari arah sirkulasi kendaraan dan jalur pedestrian, entrance akan diletakkan di sisi tapak yang menjauhi hoek sehingga tidak menggangu sirkulasi kendaraan dan exit akan akan diletakkan di sisi yang mendekati pertigaan, hal ini juga dapat mencegah para pengguna melewati entrance ke dalam bangunan secara tidak sengaja. 


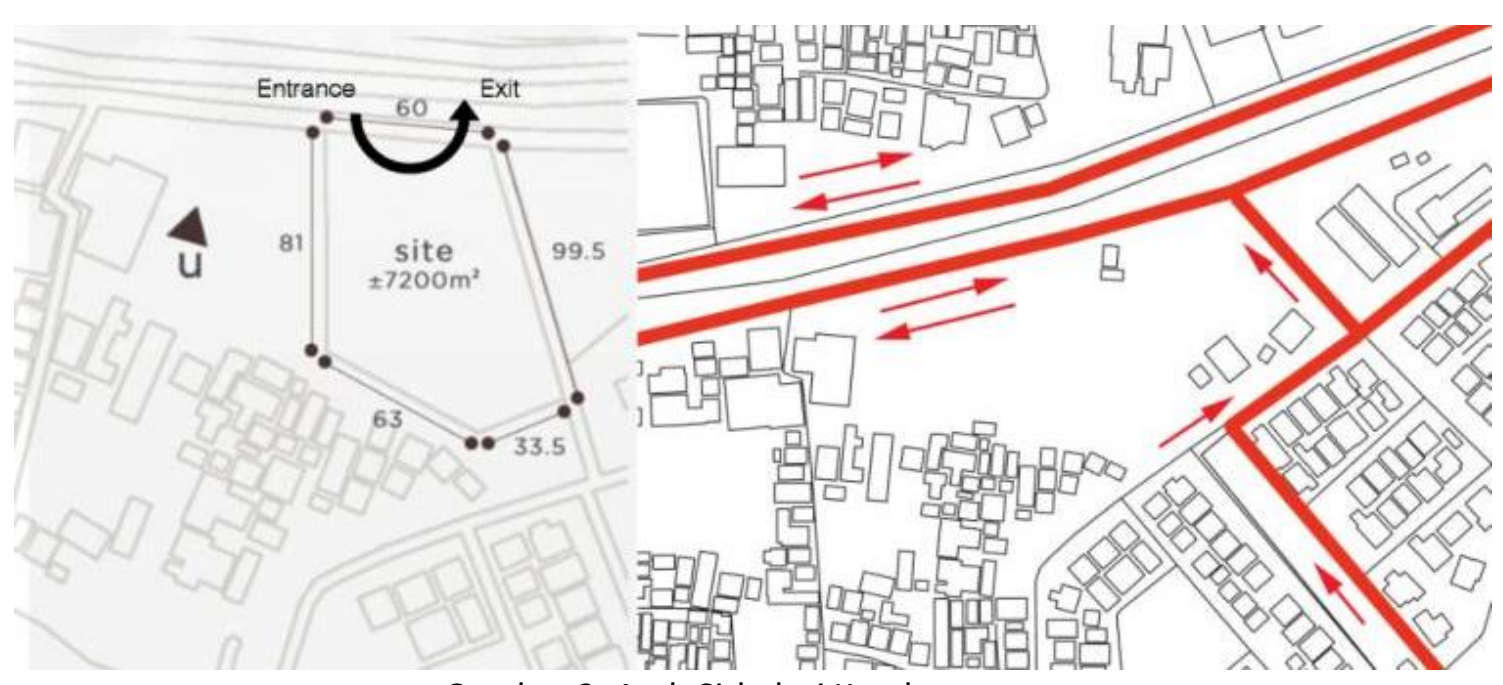

Gambar 3. Arah Sirkulasi Kendaraan

Sumber: Penulis, 2020

\section{DISKUSI DAN HASIL}

Berdasarkan dari teori-teori utama tempat ketiga dan hasil analisa, survey dan interview kawasan ditentukan program-program utama dalam bangunan sebagai berikut:

1. Pet Park

Pengguna utama fungsi ini ditujukan untuk warga Perumahan Kebon Jeruk Baru yang tidak mempunyai tempat leluasa dan aman untuk membawa jalan-jalan hewan peliharaan mereka di area perumahan sekitar. Hal ini berpotensi membangun komunitas antara para pengguna reguler. Pet Park ini mempunyai program pendukung yaitu:

- Self-Wash Station untuk menjaga kebersihan dan kesehatan hewan setempat sekaligus meningkatkan koneksi antara pengguna dan hewan peliharaannya tanpa campur tangan pihak ketiga.

- Pet Parking dimana para pengguna dapan menitipkan hewan peliharaannya dengan waktu singkat.

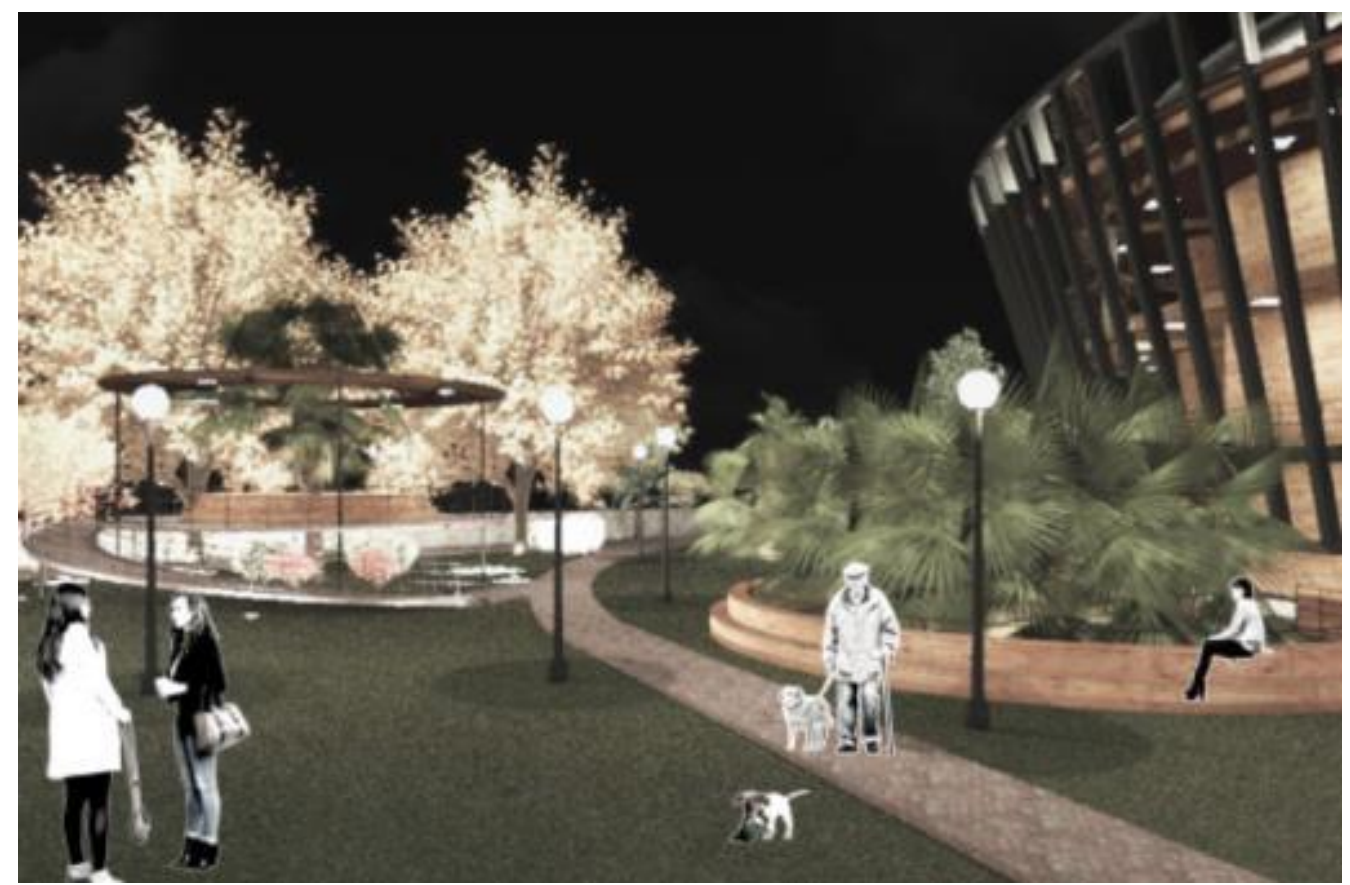

Gambar 4. Pet Park

Sumber: Penulis, 2020 


\section{Galeri}

Sebagai sebuah wadah untuk seni dalam segala bentuk yang berfokuskan kepada infortainment akan perjalanan, sejarah, dan peran hewan terhadap kehidupan manusia guna meningkatkan kesadaran manusia sebagai makhluk hidup. Galeri ini mempunyai program pendukung yaitu:

- Perpustakaan sebagai wadah informasi dan edukasi yang berhubungan dengan tujuan proyek.

- Workshop untuk tempat pertemuan dan beraktivitas pengguna-pengguna yang terlibat dalam diskusi dan kegiatan intensif pada subjek atau proyek yang ditetapkan.

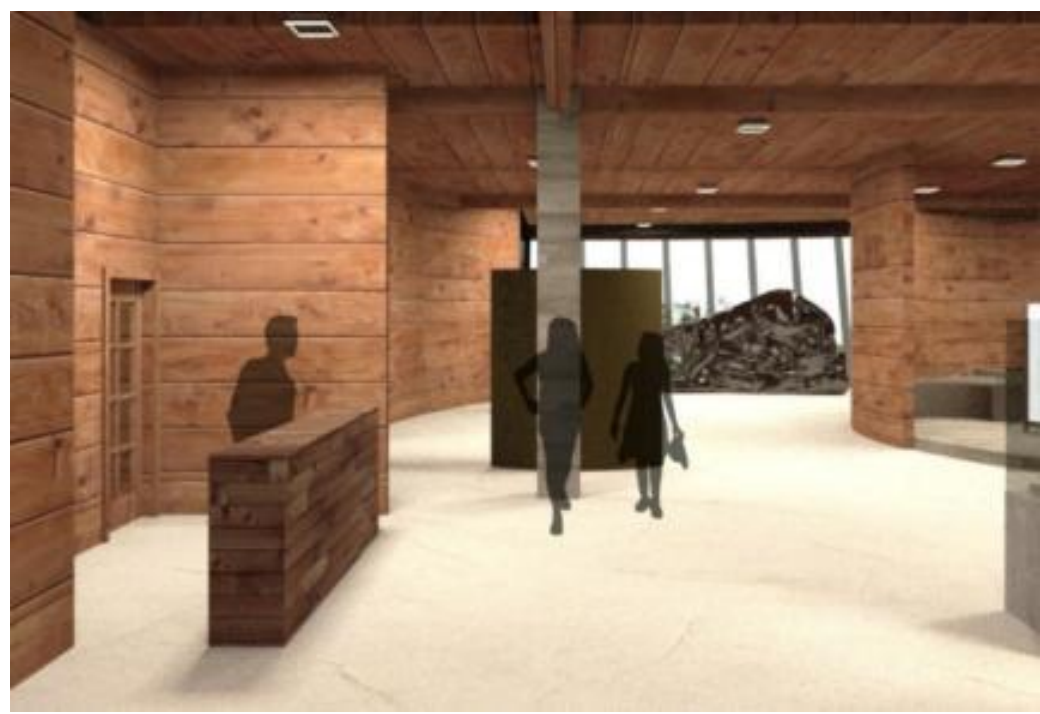

Gambar 5. Galeri

Sumber: Penulis, 2020

\section{Teater}

Sebagai wadah bentuk akhir dari pengalaman pengunjung dan kebebasan untuk bereskpresi. Untuk meningkatkan kesadaran manusia secara lebih dalam akan pengaruh dan peran hewan dalam kehidupan, nurani mereka itu sendiri, dan juga menambah pengetahuan, empati, dan koneksi emosional. Teater ini dapat menfasilitaskan hingga 266 pengunjung.

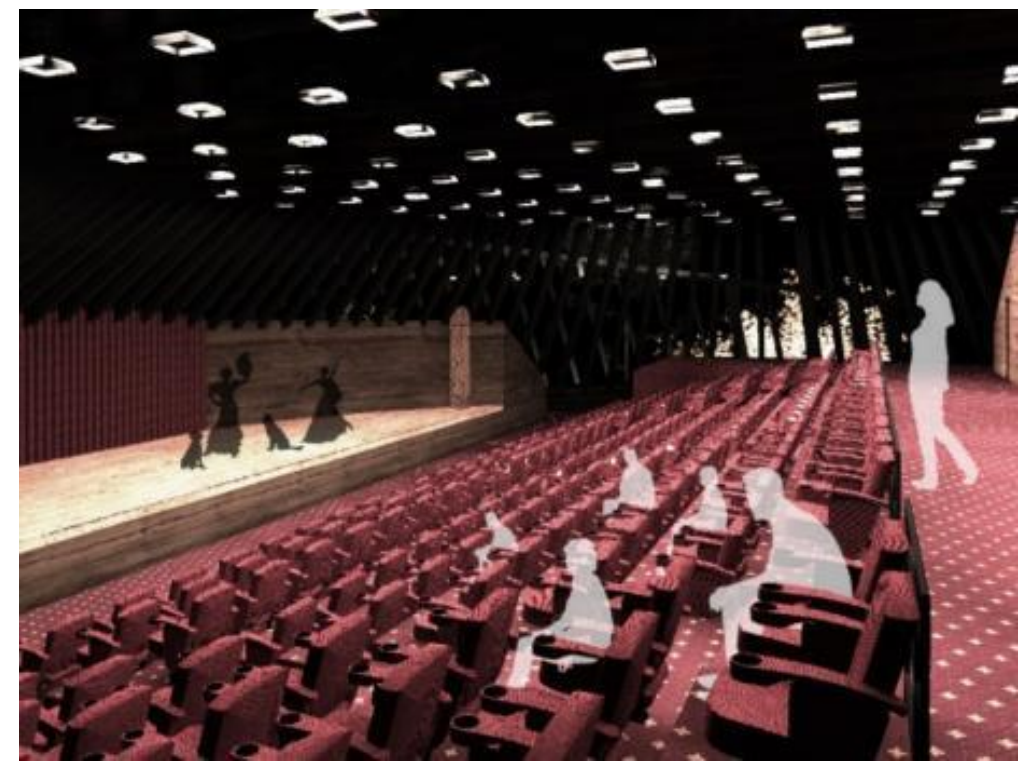

Gambar 6. Teater

Sumber: Penulis, 2020 
Proyek terbagi menjadi 3 massa yang terintegrasi sebagai bentuk dari pembagian zoning bangunan, terdapat massa yang bersifat 24 jam dengan program seperti Convenience Store dan ATM Center untuk memudahkan keperluan sehari-hari penduduk sekitar. Taman untuk hewan peliharaan diletakkan di area belakang untuk meminimalisir polusi udara dari kendaraan dan mengurangi pemicu bagi hewan peliharaan, hal ini juga mengecilkan resiko kecelakaan hewan peliharaan terlepas ke jalan raya.

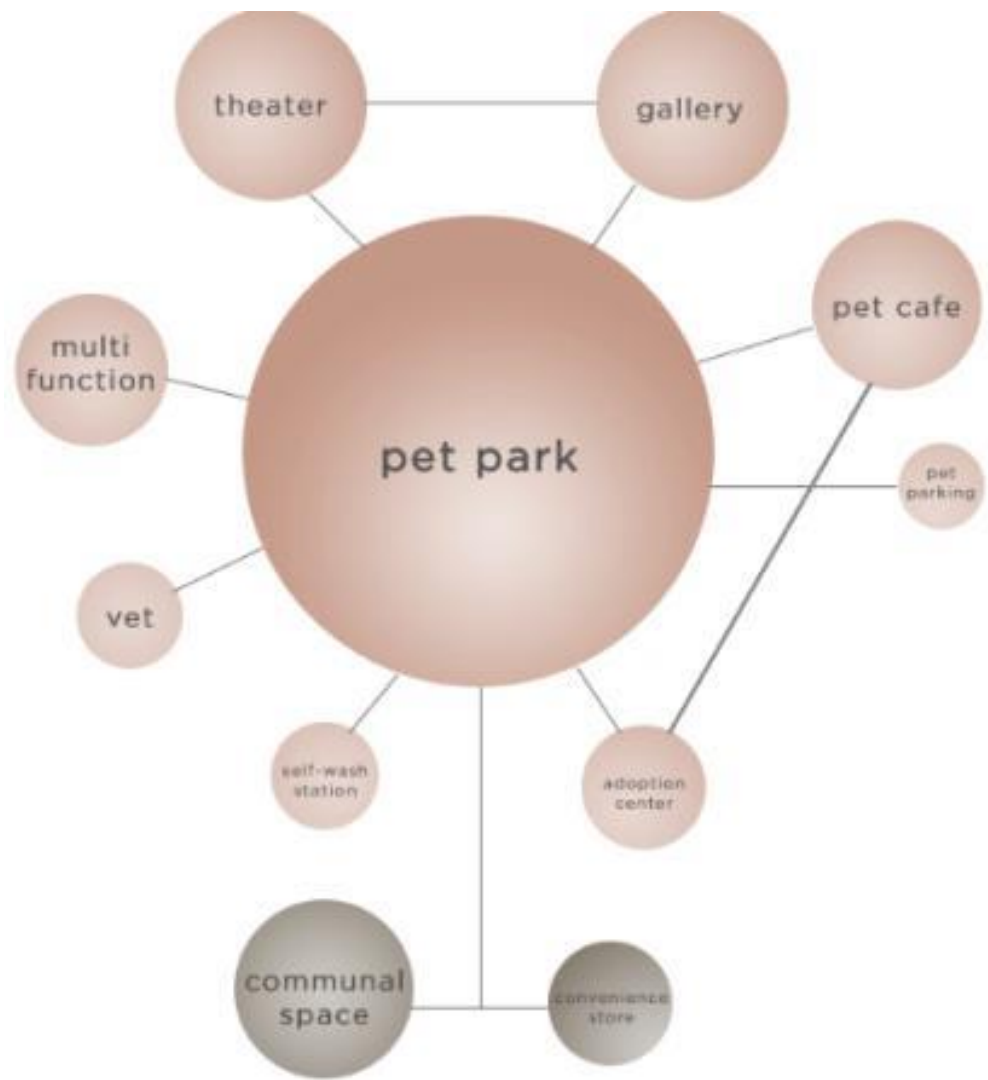

Gambar 7. Bubble Zoning

Sumber: Penulis, 2020

Taman juga diletakkan lebih dekat dengan Pemukiman Kebon Jeruk Baru dengan akses tersendiri yang diperuntukan warga sekitar yang terletak di sisi Jl. Perumahan Kebon Jeruk Baru. Jarak antara taman dan pemukiman mengikuti peraturan taman hewan yaitu mempunyai peminimalan jarak sebanyak 15 meter dari pemukiman warga, dan pohon-pohon diletakkan di sekitar tapak sebagai buffer kebisingan. Taman dilengkapi dengan gazebo sebagai tempat peristirahatan dan kolam hewan peliharaan untuk bermain, sedangkan sisa ruang berkonsep open space dengan rintangan atau objek yang minimal sehingga dapat digunakan oleh pengguna sebebas mungkin. Pusat adopsi yang bersifat sementara diletakkan di tengah bangunan dengan area bermain hewan yang dapat terlihat bebas dengan harapan dapat menarik pengunjung. Taman Hewan dibuat secara luas dan tanpa rintangan, sehingga para pengunjung dapat memodifikasi peralatan-peralatan bermain yang ingin diletakkan di dalam taman, Taman bermain akan dibangun dengan material dan struktur yang tidak bersifat permanen dan dapat diubah-ubah. Hal ini menimbulkan suatu rasa kebanggaan dan kepemilikan dan dapat mendorong pengguna untuk menjaga kenyamanan dan kelangsungan ruang itu sendiri. 
Tabel 2. Program Ruang

\begin{tabular}{|c|c|c|c|}
\hline Lantai & Nama Ruangan & Luas Per (m2) & Persentase \\
\hline \multirow{13}{*}{1} & Pusat Adopsi (7.3\%) & \multirow{13}{*}{1900} & \multirow{13}{*}{$30.4 \%$} \\
\hline & Total (+ Sirkulasi) : $141 \mathrm{~m} 2$ & & \\
\hline & Self-Wash Station $(4.83 \%)$ & & \\
\hline & Pet Parking (2.34\%) & & \\
\hline & Dokter Hewan (8.84\%) & & \\
\hline & Total (+ Sirkulasi) : $170 \mathrm{~m} 2$ & & \\
\hline & Toserba $(10.6 \%)$ & & \\
\hline & Total (+ Sirkulasi) : $204 \mathrm{~m} 2$ & & \\
\hline & R.Komunal $(17.6 \%)$ & & \\
\hline & Lobby $(5.56 \%)$ & & \\
\hline & Pet Park (Outdoor) & & \\
\hline & Service $(7.02 \%)$ & & \\
\hline & Total (+ Sirkulasi) : $135 \mathrm{~m} 2$ & & \\
\hline \multirow{7}{*}{2} & R.Multifungsi (30.5\%) & \multirow{7}{*}{1800} & \multirow{7}{*}{$28.8 \%$} \\
\hline & Total (+ Sirkulasi) : $555 \mathrm{~m} 2$ & & \\
\hline & Rooftop garden (Outdoor) & & \\
\hline & Pet Café (10.1\%) & & \\
\hline & Total (+ Sirkulasi) : $185 \mathrm{~m} 2$ & & \\
\hline & Service $(7.42 \%)$ & & \\
\hline & Total (+ Sirkulasi) : $135 \mathrm{~m} 2$ & & \\
\hline \multirow{6}{*}{3} & Galeri $(38.5 \%)$ & \multirow{6}{*}{995} & \multirow{6}{*}{$15.92 \%$} \\
\hline & Perpustakaan (12.8\%) & & \\
\hline & Infotainment Center (8\%) & & \\
\hline & Workshop (7.3\%) & & \\
\hline & Service $(13.5 \%)$ & & \\
\hline & Total (+ Sirkulasi) : $135 \mathrm{~m} 2$ & & \\
\hline \multirow{5}{*}{4} & Teater $(51.3 \%)$ & \multirow{5}{*}{890} & \multirow{5}{*}{$14.24 \%$} \\
\hline & Stage $(8.96 \%)$ & & \\
\hline & Back Stage $(10.5 \%)$ & & \\
\hline & Service $(15.12 \%)$ & & \\
\hline & Total (+ Sirkulasi) : $135 \mathrm{~m} 2$ & & \\
\hline \multirow{11}{*}{ B1 1} & Canine Gym (15.8\%) & \multirow{11}{*}{2900} & \multirow{11}{*}{-} \\
\hline & Total (+ Sirkulasi) : $466 \mathrm{~m} 2$ & & \\
\hline & Kennel $(4.42 \%)$ & & \\
\hline & Total (+ Sirkulasi) : $130 \mathrm{~m} 2$ & & \\
\hline & Training Center $(6.32 \%)$ & & \\
\hline & Total (+ Sirkulasi) : $186 \mathrm{~m} 2$ & & \\
\hline & R.Staff Sevice $(0.78 \%)$ & & \\
\hline & R. Tunggu Supir $(0.47 \%)$ & & \\
\hline & CCTV/Satpam $(0.78 \%)$ & & \\
\hline & Service $(4.59 \%)$ & & \\
\hline & Total (+ Sirkulasi) : $135 \mathrm{~m} 2$ & & \\
\hline
\end{tabular}

Sumber: Penulis, 2020 


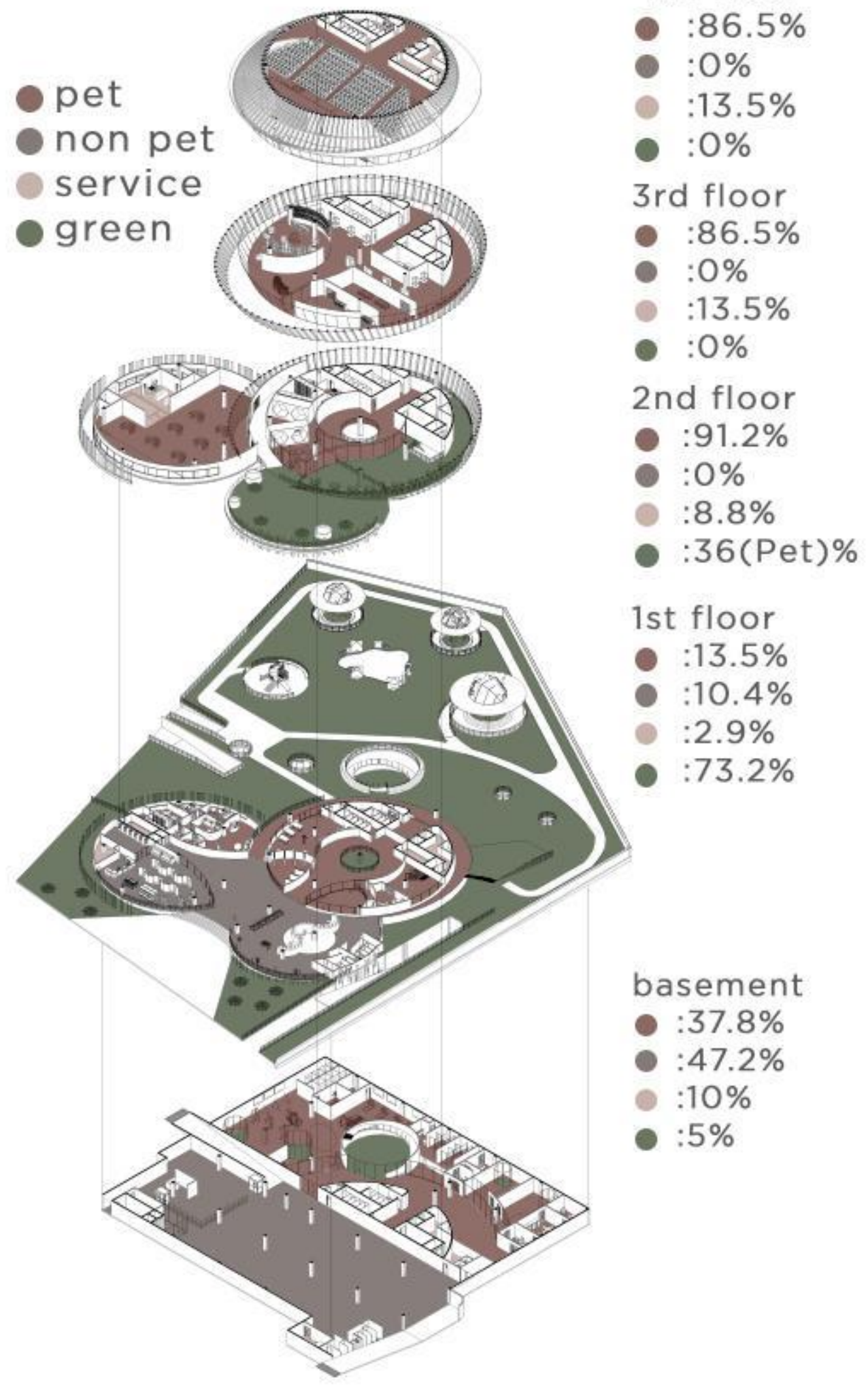

4th floor

Gambar 8. Pembagian Zona Bangunan Sumber: Penulis, 2020 


\section{KESIMPULAN DAN SARAN}

Hewan peliharaan di wilayah dapat menjadi katalisator untuk beberapa dimensi hubungan sosial manusia di lingkungan, mulai dari interaksi sosial dan personal, hingga penjalinan relasi. Bagi banyak pemilik hewan peliharaan, hewan peliharaan mereka juga memfasilitasi hubungan dimana mereka memperoleh bentuk dukungan sosial yang nyata, baik yang bersifat praktis maupun yang mendukung secara emosional. Hewan peliharaan juga bermanfaat dalam peningkatan kualitas hidup secara fisik dan mental.

Program - program dalam Taman Hewan Peliharaan dan Teater Kebon Jeruk disesuaikan untuk kebutuhan pengguna-pengguna First maupun Second Place sekitarnya seperti Pet Cafe untuk penghilang stres bagi pekerja dan murid, Canine Gym sebagai sarana olahraga alternatif pengguna fasilitas kesehatan sekitar, dan menyediakan taman sebagai tempat dimana para pemilik hewan di area sekitar dapan membawa hewan peliharaan dengan aman dan leluasa. Proyek ini juga berpacu untuk menjadi sebuah Thirdspace dengan meningkatkan kesadaran moral manusia sebagai sebuah species terhadap hewan melalui program Galeri dan Teater.

Taman Hewan Peliharaan dan Teater Kebon Jeruk dapat menjadi tempat dimana para pengguna dapat membentuk sebuah komunitas bagi para pecinta hewan dan membangun kembali hubungan dan relasi sosial para individualis akibat fenomena global dimana sifat individualisme semakin meningkat dan sebaliknya hubungan dan relasi sosial menurun akibat peningkatan pembangunan sosial-ekonomi di kota-kota besar.

Maka proyek ini juga diharapkan untuk menjadi tempat ketiga yang dapat mengakomodasi para pengguna agar dapat berinteraksi dan menukar informasi dengan rasa nyaman dan menyenangkan, dan membangkitkan kesadaran baru akan kasih sayang manusia dan alam semesta.

\section{REFERENSI}

Allen, K., Blascovich, J., Mendes W.B. (2002). Cardiovascular reactivity and the presence of pets, friends, and spouses: the truth about cats and dogs. Psychosom Med. Sep-Oct;64(5):727-39.

Eddy, J., Hart, L. A., \& Boltz, R. P. (1988). The effects of service dogs on social acknowledgments of people in wheelchairs. Journal of Psychology, 122, 39-45

Johnson, R.A. (2011). Animal-assisted interventions in health care contexts. In McCardle P, McCune S, Griffin JA \& Maholmes V (Eds.), How animals affect us (pp. 183-192). Washington D.C.: American Psychological Association.

Lefebvre, H. (1974). The Production Of Space . Blackwell

McNicholas, J., Collis, G.M. (2000). Dogs as catalysts for social interactions: robustness of the effect. Br J Psychol;91:61-70.

Oldenburg, R. (1999). Great Good Place. New York: Marlow. p.16

Pete, M. (2012). Going Home: Essays, Articles, and Stories in Honour of the Andersons. Lulu.com. p. 37. ISBN 978-1-291-12167-4.

Raina, P., Waltner-Toews, D., Bonnett, B., Woodward, C., Abernathy, T. (1999). Influence of companion animals on the physical and psychological health of older people: an analysis of a one-year longitudinal study. J Am Geriatr Soc. Mar;47(3):323-9.

Regan, T. (1983). The Case for Animal Rights. University of California Press.

Singer, P. (1975). Animal liberation: A New Ethics for our Treatment of Animals. New York

Soja, E. W. (1996). Thirdspace. Malden (Mass.): Blackwell.

White, R. (July-August 2018). "A third place". New Zealand Geographic (152): 6

Wood L, Martin K, Christian H, Nathan A, Lauritsen C, Houghton S, et al. (2015) The Pet Factor Companion Animals as a Conduit for Getting to Know People, Friendship Formation and Social Support. PLoS ONE 10(4): e0122085. <https://www.petfairasia.com/en/asiamarkets/southeast-asia-pet-market/. (1/24/2020) 
